\title{
The frontal sinus- physiological and pathophysiological aspects- an endoscopist's perspective: a review
}

\author{
Manish Munjal $^{1 *}$, Sanjeev Puri ${ }^{1}$, Garima Matta ${ }^{2}$, Shubham Munjal ${ }^{2}$ \\ ${ }^{1}$ Department of ENT, ${ }^{2}$ Department of Physiology, Dayanand Medical College, Ludhiana, Punjab, India
}

Received: 18 July 2020

Revised: 01 September 2020

Accepted: 07 September 2020

\author{
*Correspondence: \\ Dr. Manish Munjal, \\ E-mail: manishmunjaldr@yahoo.com
}

Copyright: ( $)$ the author(s), publisher and licensee Medip Academy. This is an open-access article distributed under the terms of the Creative Commons Attribution Non-Commercial License, which permits unrestricted non-commercial use, distribution, and reproduction in any medium, provided the original work is properly cited.

\begin{abstract}
In this era of minimally invasive surgical interventions, the knowledge of the physiology and pathophysiology of the frontal sinus is vital to the endoscopic rhinologist. The conventional procedure of sinus surgery has given way to functional endoscopic sinus surgery whereby now the emphasis is not on cleaning the sinus but reverting the function of the sinus. The surgery is only done at the frontal recess only. The physiology and pathophysiology of the frontal sinus needs an introspection.
\end{abstract}

Keywords: Frontal sinus, Physiology, Pathophysiology, Endoscopic surgery

\section{INTRODUCTION}

Galen in 691 AD noted the existence of the paranasal sinuses. Vesalius in early 16th century described the frontal, maxillary, and the sphenoid sinuses. ${ }^{1}$

The frontal sinuses, one on either side lie deep to the supraciliary ridges, between the outer and inner tables of the frontal bone. They are rarely symmetrical; the septum between them usually deviating from the median plane. The frontal sinus is usually larger in men compared to in women. $4 \%$ of the population fail to develop both the frontal sinuses. ${ }^{2,3}$

Historically, major frontal sinus surgery has only existed for the last 115 years. The concept of the frontal recess, as the frontal sinus drainage pathway was conceived by Killian in 1896. Surgical management of frontal sinus disease was first described in the 19 th century. ${ }^{4,5}$

The frontal sinus was first described by Volcher Coiter of Holland, a pupil of Fallopius and Eustachius in the 16th century. Berengario ad Capri in the 16th century described the frontal bone region as having "two tables within which there is notable vacuity so as to not weigh down the body." Da Vinci in 1489 first recognized its existence and illustrated its morphology. Schaffer 1916 coined the term "frontal sinus". 6

The frontal sinus remains the most challenging paranasal sinus to treat even with the advent of endoscopic sinus instrumentation. ${ }^{7}$

\section{DISCUSSION}

Frontal sinus is lined by ciliated pseudostratified columnar epithelium, which is thin and pink in colour. Underneath lies the tunica propria which contains different types of cells and glands, that secrete mucus. Number of goblet cells is about $5900 / \mathrm{mm}^{2}$ and seromucinous glands about $0.08 / \mathrm{mm}^{2}{ }^{8}{ }^{8}$

Frontal sinus drains towards the middle meatus and requires a patent sinus ostium and a healthy lining mucosa. Healthy mucosa means normally functioning cilia and mucus secretion of normal viscosity and elasticity. 
Ventilation prevents hypoxia in sinus and avoids subsequent transudation of serous fluid, ciliary dysfunction, and mucus gland dysfunction. ${ }^{9}$

The cilia beat in a synchronized fashion, with only the tips propelling the gel phase during their active beat, and remain within the sol phase during recovery, thereby propelling the gel phase during their active beat. The beat frequency ranges from 8 to 20 beats per second. ${ }^{10}$

Stammberger's endoscopic observations indicate that mucus layer is renewed two to three times per hour. ${ }^{9}$ The frontal sinus is unique in its mucociliary clearance, as this is the only sinus in which an inherent recirculation phenomenon occurs. Mucus is actively transported into the sinus along the intersinus septum. Mucus then travels laterally across the roof of the sinus to the lateral wall, then to the floor and finally, either enters the frontal sinus infundibulum or recirculates through the intersinus septum. $^{5}$

Thus, an unspecified amount of mucus and debris may recycle through the frontal sinus. ${ }^{10}$

Hilding 1932 demonstrated that the mucous blanket travels in a spiral manner towards the internal ostium in a way that effectively defies gravity.12 Messerklinger 1967 confirmed Hilding's work 35 years later with an additional discovery that a portion of the mucus blanket recirculates within the frontal sinus and frontal recess, while the remaining mucus enters the middle meatus. ${ }^{11,12}$

Mucus blanket in most cases is able to bypass many anatomical obstructions. At some area's secretions may be temporarily retained until their surface tension, cohesion, and viscosity combined with gravity enables them to overcome these obstacles. ${ }^{10}$

After passing through the ostium, mucus enters the narrow clefts that form the frontal recess, which ultimately joins the Osteomeatal complex (OMC).

The drainage pathway of the frontal sinus has an 'hourglass pattern', composed of three different regions. ${ }^{13}$

- The upper/top region is the frontal infundibulum, the cleft within the inferior-most aspect of frontal sinus forms an upright funnel that narrows towards the inferior, posterior and medial direction.

- The waist/middle region is represented by the frontal sinus ostium, found postero-medially in the sinus, at the most inferior aspect of frontal infundibulum.

- The lower/bottom region is formed by the frontal recess, the narrow cleft within the anterior ethmoid complex that forms an inverted funnel that widens in inferior and posterior direction.
Ciliary-beat frequency (CBF) is an important factor influencing mucociliary flow in the respiratory tract. A significant correlation exists between $\mathrm{CBF}$ and mucus transport time (MTT), which suggests that CBF is the main factor in nasal mucociliary clearance in healthy individuals. ${ }^{14}$

From the frontal sinus the mucus flows

$\downarrow$

Frontal infundibulum

Frontal sinus ostium

Frontal sinus recess

$\downarrow$

Qsteomeatal unit /complex

$\downarrow$

Middle meatus

$\downarrow$

Drains into the nose, from the posterior choanae

Reaches the nasopharynx and pharynx

$\downarrow$

Swallowed and destroyed in the stomach

Figure 1: Flow chart of frontal sinus drainage.

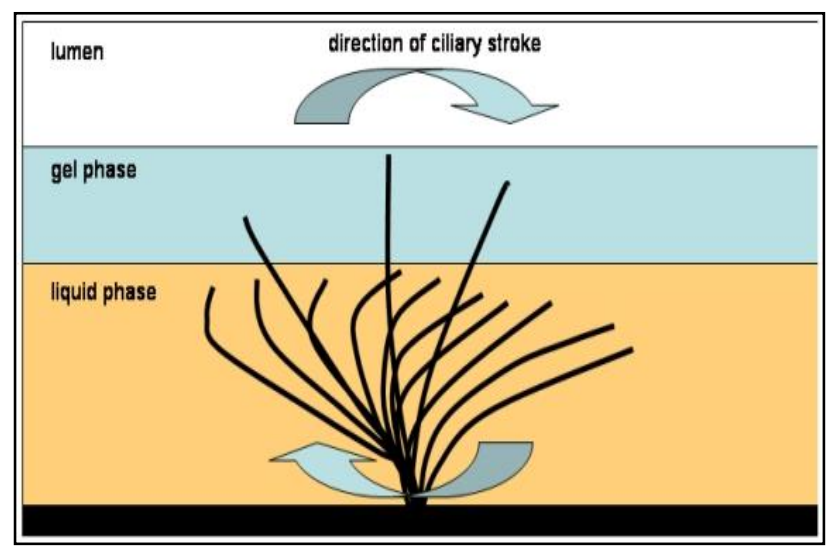

Figure 2: Ciliary stroke in nasal mucosa ${ }^{15}$ 


\section{The frontal sinus pathophysiology}

Any pathology in the sinuses is due to abnormal mucociliary flow resulting from alteration in the normal ventilation or drainage of the sinuses.

In the pathogenesis of sinus pathology, the presence of "mucosal contact" areas is the single most important factor. Messerklinger 1978. Various etiologies are responsible for the obstruction of the mucociliary drainage pathway. ${ }^{16}$

Narrowing of the frontal sinus drainage pathway at any of its bony surroundings, due to mucosal oedema, polyps, scarring, and adhesions secondary to trauma, infection, or previous surgery may lead to frontal sinus obstruction. ${ }^{17}$

\section{Etiological/predisposing factors}

Mackay IS and Lund VJ 1997 stated the predisposing factors as: anatomical variants, mucociliary abnormalities include primary-primary ciliary dyskinesia cystic fibrosis Young's syndrome and secondary-allergy, bacterial infection. ${ }^{18}$. Mucociliary clearance can be impaired by: hypoxia, temperature variations, dehydration, medications (antihistamines and anticholinergics), cigarette smoke, foreign bodies, infections, environmental irritants, trauma, tumours, primary immune deficiency or secondary due to Human immunodeficiency (HIV) infection or immunosuppressant drugs and allergy.

More than $90 \%$ of frontal and maxillary sinusitis is due to pathology in the anterior ethmoid region and limited surgery to treat these distal sites can re-establish ventilation and drainage.

Messerklinger found the incidence isolated sphenoid sinus disease to be about $2 \% .{ }^{19}$ In the present era the physiology and pathophysiology of the frontal sinuses is of paramount importance as endoscopic surgery aims to be minimally invasive with emphasis only on the frontal recess and ostium of the frontal sinus. The obstructive pathology is removed under magnified endoscopic visualisation thereby facilitating drainage and ventilation of the frontal sinus. The aerobic environment reverts the mucociliary function and the sinus starts clearing by itself. ${ }^{20}$ In case of mucocele the frontal sinus is most commonly involved owing to obstruction of natural ostia of the frontal sinus which impairs the drainage. ${ }^{21,22}$ Ciliary immobility can lead to increased mucus viscosity, further blocking drainage. Bacteria are introduced into the sinuses by coughing and nose blowing causing further infection. ${ }^{23}$

\section{CONCLUSION}

The frontal sinus sinus is an essential part of the immune defence/air filtration carried out by the nose. The anatomic features that often compromise ventilation and drainage of the frontal sinus also limit the effectiveness of medical and surgical management.
Funding: No funding sources

Conflict of interest: None declared

Ethical approval: The study was approved by the Institutional Ethics Committee

\section{REFERENCES}

1. Schaffer JP. The genesis, development and adult anatomy of the nasofrontal region in man. Am J Anat. 1916;20:125-46.

2. Schaffer JP. The nose, paranasal sinuses, nasolacrimal passageways and olfactory organ in man. Philadelphia, Blakiston; 1920.

3. Som PM, Curtin HD. Head and Neck Imaging, 3rd editon. Chicago, Mosby Year Book. 1996.

4. Killian G. Anatomic der Nase menschilcher Embryonen. Arch Laryngol Rhinol (Berl). 1895;3:17-47.

5. Killian G. Die Killian sche radicaloperation chronischer stirnhohleneuterungen. II. Weisteres Kasuistisches Material and zusammenfassung. Arch Laryngol Rhinol. 1903;13:59.

6. Da Vinca L. Quaderni d' anatomia, I-IV. In: Fogli della Royal Library di Windsor, pubblicati da CL Vangensten, A Fonahen, H Hopstock Christiania: F Dybwad. 1489:1911-16.

7. McLaughlin RB, Rehl RM, Lanza DC. Clinically relevant frontal sinus anatomy and physiology. Otolaryngologic Clinics of North America. 2001;34(1):1-22.

8. Draf W, Weber R, Keerl R. Aspects of frontal sinus surgery. Part I Endonasal frontal sinus drainage for inflammatory sinus disease. HNO 1995;43:352-57.

9. Pinheiro AD, Facer GW, Kern EB. Sinusitis: Current concepts and management. In Bailey BJ (ed). Head and Neck Surgery-Otolaryngology, Philadelphia, Lippincott-Raven. 1998;441.

10. Stammberger H. Functional Endoscopic sinus surgery. Philadelphia, PA: BC Decker. 1991;70-6.

11. Messerklinger W. On the drainage of the frontal sinus of man. ActaOtolaryngol (Stockh). 1967;63:176-7.

12. Hilding A. The physiology of drainage of mucous. Am J Physiol. 1932;100:664-70.

13. Lee D, Brody R, Har-El G. Frontal sinus outflow anatomy. Am J Rhino. 1997;11:283.

14. Braverman I, Wright ED, Wang CG, Eidelman D, Frenkiel S. Human nasal ciliary-beat frequency in normal and chronic sinusitis subjects. J Otolaryngol. 1998;27(3):145-52.

15. Beule AG. Physiology and pathophysiology of respiratory mucosa of the nose and the paranasal sinuses. GMS Curr Top Otorhinolaryngol Head Neck Surg. 2010;9:Doc07.

16. Messerklinger W. Endoscopy of the nose. Baltimore, Urban Schwarzenberg. 1978.

17. Levine HL, May M. Endoscopic Sinus Surgery. New York, Thieme Medical Publishers. 1993.

18. Mackay IS and Lund VJ. Surgical management of sinusitis. Scott-Brown's Otolaryngology, 6th edition, Butterworth Heinemann, Oxford. 1997. 
19. Messerklinger W. On the drainage of the frontal sinus of man. Acta Otolaryngol (Stockh). 1967; 63:176-7.

20. Wigand ME, Hosemann WG. Endoscopic sinus surgery for frontal sinusitis and its complications. Am J Rhinol. 1991;5:85.

21. An unusual presentation of a giant frontal sinus mucocele manifesting with a subcutaneous forehead mass. Tan CS, Yong VK, Yip LW, Amrith S Ann Acad Med Singap. 2005;34(5):397-8.

22. Aggarwal SK, Bhavana K, Keshri A, Kumar R, Srivastava A. Frontal sinus mucocele with orbital complications: Management by varied surgical approaches. Asian journal of neurosurgery. 2012;7(3):135-140.
23. Battisti AS, Modi P, Pangia J. Sinusitis. [Updated 2020 Aug 10]. In: StatPearls [Internet]. Treasure Island (FL): StatPearls Publishing; 2020 Jan-. Available from: https://www.ncbi.nlm.nih. gov/books/NBK470383/. Last accessed on 08 June 2020.

Cite this article as: Munjal M, Puri S, Garima Matta G, Munjal S. The frontal sinus- physiological and pathophysiological aspects- an endoscopist's perspective: a review. Int J Otorhinolaryngol Head Neck Surg 2020;6:1937-40. 